\title{
CONSIDERAÇÕES SOBRE STEPHOMYIA TAVARES (DIPTERA, CECIDOMYIIDAE, ASPHONDYLIIDI), COM DESCRIÇÃO DE QUATRO ESPÉCIES NOVAS ASSOCIADAS COM EUGENIA L. E NEOMITHRANTHES OBSCURA (DC.) LEGR. (MYRTACEAE)
}

\author{
Valéria Cid Maia ${ }^{1}$
}

\begin{abstract}
CONSIDERATIONS ON STEPHOMYIA TAVARES (DIPTERA, CECIDOMYIIDAE, ASPHONDYLIIDI), WITH DESCRIPTION OF FOUR NEW SPECIES ASSOCIETED WITH EUGENIA L. E NEOMITHRANTHES OBSCURA (DC.) LEGR. (MYRTACEAE). Stephomyia rotundifoliorum, sp.n., S. tetralobae, sp.n., S. espiralis, sp.n. and S. mina, sp.n. from Rio de Janeiro State are described. A brief diagnosis of the genus and two keys are presented - one to larvae of the known species and one for available males. The new species are recorded from various species of Eugenia L. and Neomithrantes obscura (DC) Legr. (Myrtaceae).

KEY WORDS. Diptera, Cecidomyiidae, Stephomyia, Myrtaceae, Rio de Janeiro, Brazil
\end{abstract}

Stephomyia Tavares, 1916 baseia-se em material proveniente do Jardim Botânico do Rio de Janeiro. S. eugeniae Tavares, 1916 era a única espécie no Brasil até então incluída neste gênero, encontrada em Eugenia sp. (Myrtaceae).

Neste trabalho são apresentadas as descrições de quatro espécies novas de Stephomyia: S. rotundifoliorum, S. tetralobae, S. espiralis e $S$. mina, de suas respectivas galhas, bem como registrados novos hospedeiros para as espécies. Uma breve diagnose deste gênero e chaves para segregação das espécies, baseadas na morfologia do macho e da larva são também fornecidas.

\section{Stephomyia Tavares, 1916}

Diagnose. Palpo curto; flagelômeros com circunfila formando reticulações em toda a sua superfície; ovipositor pouco protátil, terminando em dois lobos em forma de lamela.

Considerações. Gênero neotropical com cinco espécies conhecidas, incluindo as descritas neste trabalho. Até o momento, as plantas assinaladas na literatura como hospedeiros de Stephomyia pertenciam a um único gênero: Eugenia L., 1753 (Myrtaceae). Os seguintes novos registros são assinalados: Eugenia copacabanensis Kiaers., 1893 para S. tetralobae, sp.n. e S. espiralis, sp.n.;

1) Museu Nacional do Rio de Janeiro, Quinta da Boa Vista, 20940-040 Rio de Janeiro, Rio de Janeiro, Brasil. Bolsista da FAPERJ. 
E. rotundifolia Casar, 1842 para S. rotundifoliorum, sp.n. e Neomitranthes obscura (DC.) Legr. (Myrtaceae) para S. mina, sp.n.. Esta é a primeira ocorrência do gênero em Neomitranthes Legr., 1977.

Dentre as espécies estudadas, $S$. rotundifoliorum não apresenta um dos caracteres genéricos citados na descrição de TAVARES (1916): palpo uniarticulado. No entanto, a espécie foi incluída neste gênero baseado, principalmente, nos seguintes caracteres: flagelômeros antenais com circunfila, formando reticulações em toda a sua extensão; ovipositor com dois lobos apicais em forma de lamela; terminália masculina com hipoprocto e cerco reduzidos.

\section{Chave para segregação das larvas das espécies de Stephomyia}

1. Espátula protorácica com dois lobos apicais ...................

- Espátula protorácica com quatro lobos apicais ................ 4

2. Segmento abdominal VIII com espiráculo .................. 3

- Segmento abdominal VIII desprovido de espiráculo ........... eugeniae

3. Espátula protorácica com dentes apicais triangulares com ápice pontiagudo mina

- Espátula protorácica com dentes apicais alongados com ápice arredondado .

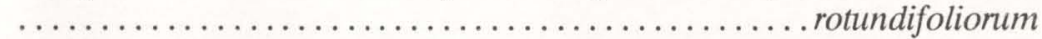

4. Lobos laterais desenvolvidos (cerca da metade do comprimento dos lobos medianos) (Fig. 14) ............................tetralobae

- Lobos laterais reduzidos (com menos de 1/4 do comprimento dos lobos medianos) (Fig. 21) ........................... espiralis

Chave para segregação dos machos de Stephomyia eugeniae, $S$. rotundifoliorum e $S$. mina.

$S$. tetralobae e $S$. espiralis não constam nesta chave, porque os machos não são conhecidos.

1. Palpo com dois artículos; edeago alongado com uma pequena reentrância mediana no ápice; hipoprocto com uma cérda bem mais longa que as demais na extremidade de cada lobo (Fig. 3) ......... rotundifoliorum

- Palpo com um único artículo; edeago alongado sem reentrância mediana no ápice; hipoprocto com cerdas aproximadamente do mesmo comprimento na extremidade de cada lobo (Fig. 3 ) $\ldots \ldots \ldots \ldots \ldots \ldots \ldots \ldots \ldots \ldots$

2. Gonóstilo triangular; cerco formado por dois lobos riniformes; hipoprocto formado por dois lobos completamente separados um do outro ........ mina

- Gonóstilo ovalado; cerco formado por dois lobos arredondados; hipoprocto levemente bilobado (Fig. 78 de MÖHN, 1962) ............eugeniae 


\section{Stephomyia rotundifoliorum, sp.n.}

Figs 1-9

Diagnose. Palpo com dois artículos, macho com edeago alongado com uma pequena reentrância mediana no ápice; hipoprocto bilobado, mais longo que o cerco, com lobos triangulares e com uma cerda mais longa que as demais na extremidade de cada um; cerco bilobado, setoso, com ápice arredondado.

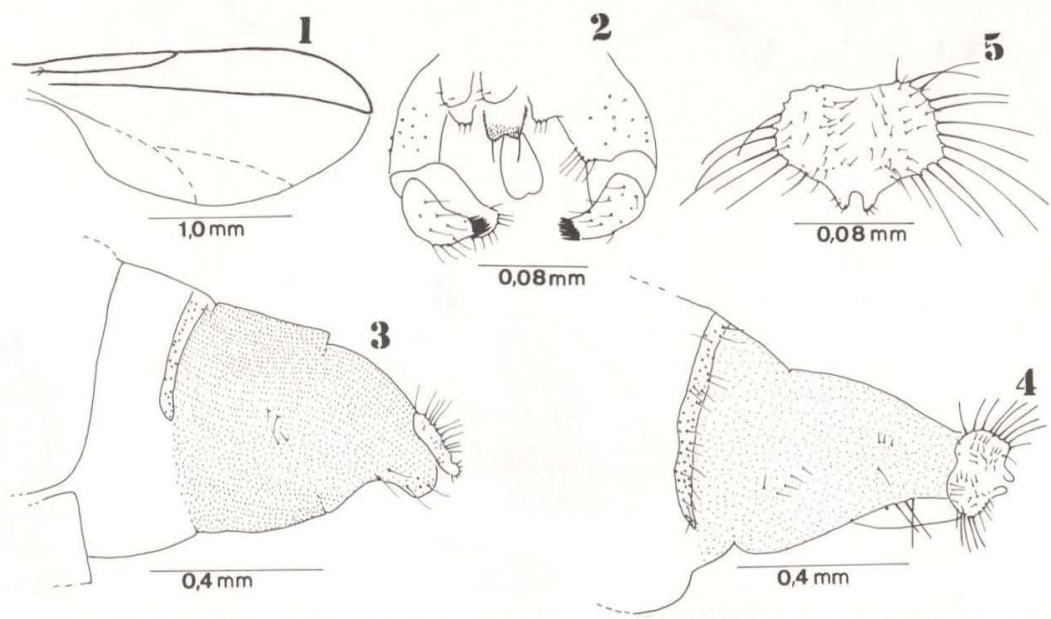

Figs 1-5. Stephomyia rotundifoliorum, sp.n. (1) Macho, asa; (2) macho, genitália, vista dorsal; (3) fêmea, ovipositor, vista lateral; (4) fêmea, ovipositor, vista dorsal; (5) fêmea, ápice do ovipositor, vista dorsal.

Macho. Comprimento do corpo: 3,16-2,62mm; comprimento da asa: 2,20-2,00 mm. Cabeça: olhos com facetas hexagonais intimamente aproximadas; antena com escapo e pedicelo transversais e 12 flagelômeros cilíndrincos com circunfila anastomosada; palpo com dois artículos; labelo com quatro cerdas laterais e cinco medianas; hipofaringe com cerdas medianas e setuloso no ápice. Tórax: comprimento da asa $-2,55-3,97 \mathrm{~mm}(\mathrm{~N}=6)$. Veia como na figura 1 . Escuto com duas fileiras irregulares dorsocentrais e duas fileiras laterais de cerdas; anepímero e anepisterno com um grupo de cerdas discais e catepisterno com algumas cerdas discais. Pernas com garras simples, curvas após o terço médio e empódio com cerca de $2 / 3$ de comprimento das garras. Abdômen: tergitos e esternitos I-VII esclerotinizados, retangulares, com cerdas em toda a sua extensão. Tergito VIII esclerotinizado, alongado, estreito e setoso. Esternito VIII pouco esclerotinizado, retangular, com cerdas em toda a sua extensão. Genitália: gonóstilo afilando à extremidade livre; edeago alongado com uma pequena reentrância mediana no ápice; hipoprocto mais longo que o cerco, levemente bilobado, setoso, com lobos triangulares com uma cerda mais longa qua as demais na extremidade; cerco formado por dois lobos completamente separados um do outro, setosos e arredondados no ápice (Fig. 2). 
Fêmea. Semelhante ao macho, diferindo no que segue. Comprimento do corpo: 4,50-3,65mm. Cabeça: flagelômeros antenais X-XII progressiva e gradualmente mais curtos; labelo com seis a oito cerdas medianas. Genitália: ovipositor estriado, pouco protátil, terminando em dois lobos setosos (Figs 3, 4, 5).
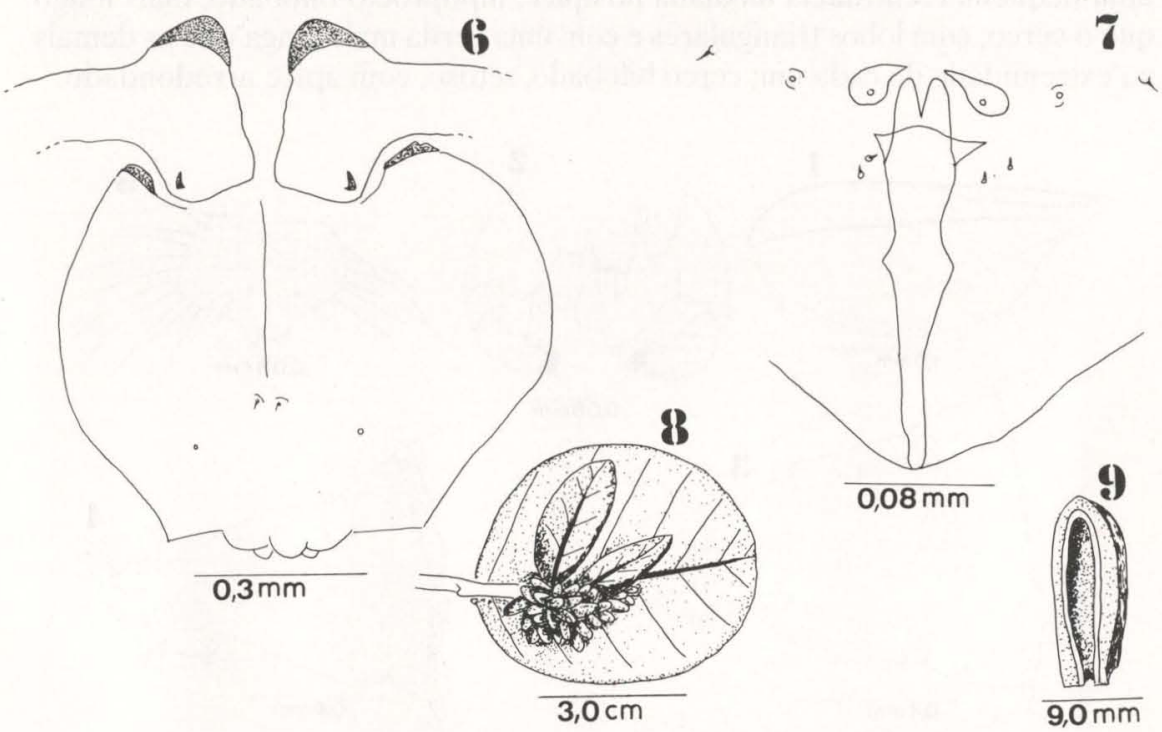

Figs 6-9. Stephomyia rotundifoliorum, sp.n. (6) Pupa, região cefálica, papilas, vista ventral; (7) larva, espátula protorácica, vista ventral; (8) galha, aspecto geral; (9) galha, secção tranversal.

Pupa. Castanho-clara. Comprimento do corpo: 2,35mm. Cabeça: chifres antenais conspícuos; espinhos frontais superior e inferior ausentes; cerda apical mais curta que a largura da antena; um par de papilas faciais laterais não setosas e um par de papilas faciais inferiores setosas (Fig. 6). Tórax: espiráculo cilíndrico e curto $(0,10 \mathrm{~mm})$. Abdômen: segmentos II-VIII cobertos por fileiras transversais de diminutos espinhos esclerotinizados. Envoltório da asa terminando próximo à metade do segmento III; envoltório das pernas atingindo o limite dos segmentos VI e VII.

Larva. Amarela. Comprimento do corpo: 2,65mm. Espátula protorácica (comprimento: $0,17 \mathrm{~mm}$ ) com dois dentes apicais longos e simples (Fig. 7); segmentos torácicos com um par de papilas esternais não setosas, dois pares de papilas laterais setosas, dois pares de papilas pleurais (o par interno não setoso e o externo setoso), um par de papilas ventrais não setosas e dois pares de papilas dorsais setosas. Segmentos abdominais I-VIII com um par de papilas pleurais setosas; segmentos abdominais I-VII com dois pares de papilas dorsais setosas, dois pares de papilas ventrais (um par anterior e um par posterior) não setosas; segmento abdominal VIII com um par de papilas dorsais setosas, um par de papilas ventrais não setoso e espiráculo; segmento anal com dois pares de papilas terminais setosas; ânus arredondado. A larva empupa na galha. 
Holótipo macho. BRASIL: Rio de Janeiro, Restinga de Barra de Maricá, I-1988, V.C. Maia leg., Museu Nacional do Rio de Janeiro (MNRJ). Parátipos de mesma procedência, coletor e coleção: um macho, 30-IV-1990; uma fêmea, I-1988; uma fêmea, 30-IV-1990; uma fêmea, 5-VI-1922. Duas exúvias, 07-XI1987; uma larva, XI-1987; oito larvas, 22-VI-1992. Com os mesmo dados do hólotipo. Obtidos de galhas foliares em Eugenia rotundifolia (Myrtaceae).

Galha. Marrom externamente e branca internamente, cilíndrica, unilocular, presente em galhos e/ou na nervura central das folhas (Figs 8,9).

$\mathrm{O}$ nome desta espécie refere-se à sua ocorrência em Eugenia rotundifolia (Myrtaceae).

\section{Stephomyia tetralobae, sp.n.}

Figs 10-15

Diagnose. Palpo com um único artículo; espátula protorácica com quatro lobos proeminentes na extremidade anterior.

Fêmea. Comprimento: 4,52mm. Cabeça: antena com 12 flagelômeros cilíndricos, escapo medindo 1,33-1,43 vezes o comprimento do pedicelo e uma vez o seu próprio diâmetro, flagelômero I com 2,90 vezes o comprimento do escapo e 4,83 vezes o seu próprio diâmetro; facetas dos olhos hexagonais; labelo com 10 cerdas; hipofaringe com cerdas medianas e setuloso no ápice; palpo com um único artículo com cinco cerdas, menor que o palpígero. Tórax: comprimento da asa: $3,10 \mathrm{~mm}$. Veias alares como em $S$. rotundifoliorum; escuto com duas fileiras irregulares dorsocentrais e duas laterais de cerdas; anepímero com um grupo de cerdas discais; anepisterno e catepisterno nús; garras simples, pouco curvas, maiores que o empódio. Abdômen: tergitos e esternitos I-VII esclerotinizados, retangulares, com cerdas em toda a sua extensão. Tergito VIII esclerotinizado, alongado, estreito e setoso; esternito VIII pouco esclerotinizado, retangular, com cerdas em toda a sua extensão. Genitália: ovipositor estriado, pouco protátil, terminando em dois lobos setosos (Figs 10 e 11).

Pupa. Castanho-clara. Comprimento do corpo: 1,63mm. Cabeça (Fig. 12): chifres antenais conspícuos; dentículo secundário inferior na base da cobertura antenal; cerda apical mais curta que a largura da antena; espinhos frontais superior e inferior ausentes; região cefálica com duas projeções laterais esclerotinizadas na margem superior; um par de faciais inferiores setosas. Tórax: espiráculo cilíndrico e curto $(0,0175 \mathrm{~mm})$. Abdômen: cobertura das asas, do par I, II e III de pernas atingindo, respectivamente, o limite dos segmentos abdominais IV e V; VI e VII; VI e VII; e VII e VIII. Segmentos II-VIII com fileiras transversais de diminutos espinhos esclerotinizados distribuídos em toda a região dorsal.

Larva. Amarela. Comprimento: 2,31mm. Antena cerca de duas vezes mais longa que larga; pescoço com um par de papilas ventrais não setosas; espátula protorácica (comprimento: $0,30 \mathrm{~mm}$ ) com quatro lobos apicais proeminentes: dois medianos mais desenvolvidos que dois laterais (Fig. 13); segmentos torácicos com um par de papilas esternais não setosas, dois pares de papilas 

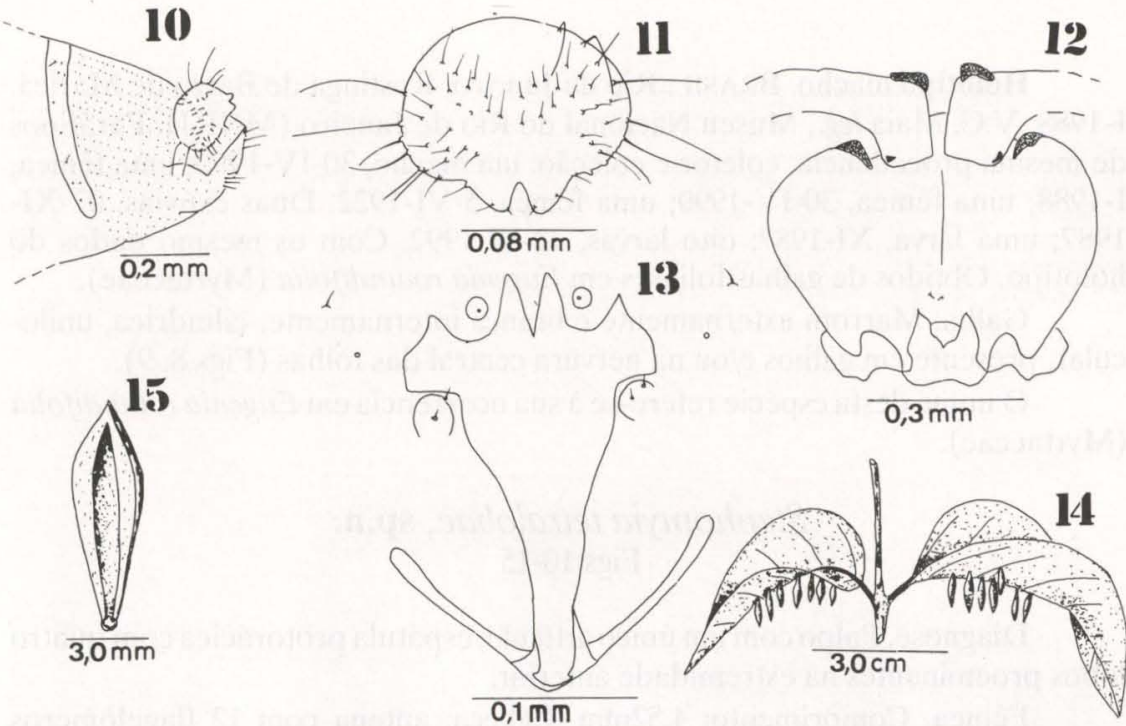

Figs 10-15. Stephomyia tetralobae, sp.n. (10) Fêmea, ovipositor, vista dorsolateral; (11) fêmea, ápice do ovipositor, vista dorsal; (12) pupa, região cefálica, vista ventral; (13) larva, espátula protorácica, vista ventral; (14) galha, aspecto geral; (15) galha, secção tranversal.

laterais setosas, dois pares de papilas pleurais (o par interno não setoso e o externo setoso) e dois pares de papilas dorsais setosas. Segmentos abdominais I-VIII com um par de papilas pleurais setosas; segmentos abdominais I-VII com dois pares de papilas dorsais setosas, dois pares de papilas ventrais (um par anterior e um par posterior) não setosas; segmento abdominal VIII com um par de papilas dorsais setosas, um par de papilas ventrais não setoso e espiráculo; segmento anal com dois pares de papilas terminais setosas; ânus arredondado. A larva empupa na galha.

Macho desconhecido.

Holótipo fêmea. BRASIL: Rio de Janeiro, Márica, Restinga de Barra de Maricá, 17-XII-1987, V.C. Maia leg. (MNRJ). Parátipos com os mesmos dados do holótipo: duas fêmeas, 17-XII-1987. Uma exúvia, 30-XI-1992; uma larva, 16-IX-1987; duas larvas, 23-X-1992. Com os mesmos dados do holótipo. Obtidos em galhas de Eugenia copacabanensis (Myrtaceae).

Galha. Cônica, verde ou vermelha, unilocular e foliar (Figs 14, 15).

$\mathrm{O}$ nome desta espécie refere-se à presença de quatro lobos proeminentes na extremidade anterior da espátula protorácica da larva.

\section{Stephomyia espiralis, sp.n.}

Figs 16-20

Diagnose. Palpo com um único artículo; espátula protorácica com dois lobos medianos desenvolvidos e dois lobos laterais reduzidos na extremidade anterior. 


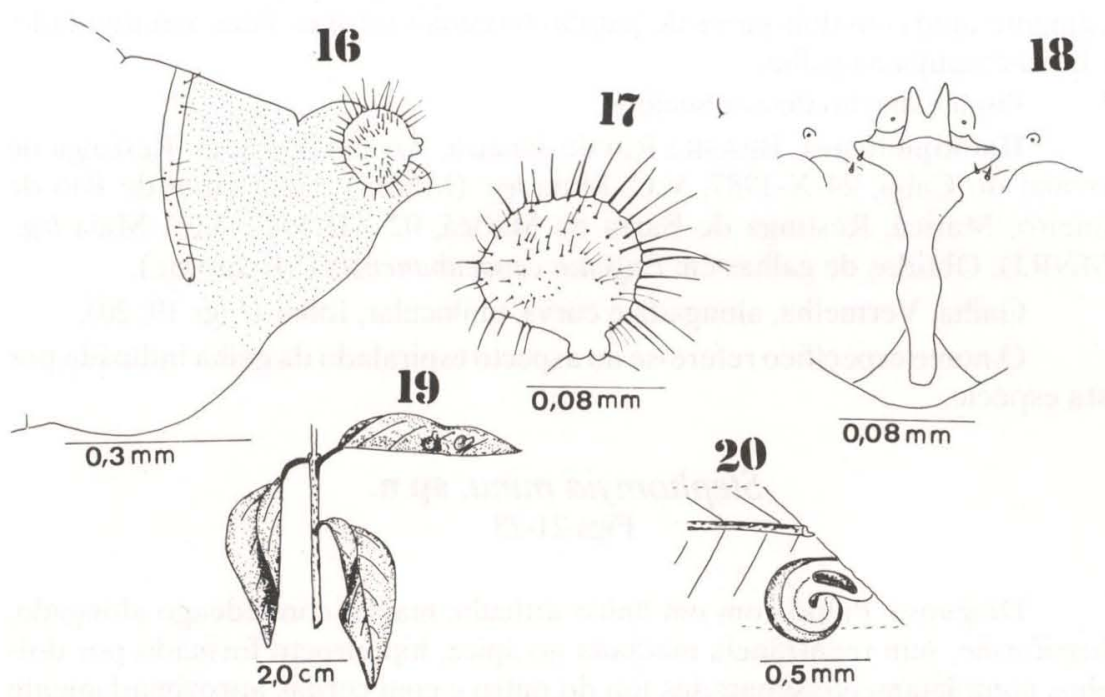

Figs 16-20. Stephomyia espiralis, sp.n. (16) Fêmea, ovipositor, vista dorsolateral; (17) fêmea, ápice do ovipositor, vista dorsal; (18) larva, espátula protorácica, vista ventral; (19) galha, aspecto geral; (20) galha secção tranversal.

Fêmea. Comprimento: 4,73mm. Cabeça: antena com 12 flagelômeros cilíndricos, escapo medindo 1,71 vezes o comprimento do pedicelo e 1,50 vezes o seu própio diâmetro, flagelômero I com duas vezes o comprimento do escapo e com quatro vezes o seu próprio diâmetro; facetas dos olhos hexagonais; labelo com oito cerdas; hipofaringe com cerdas medianas e setuloso apicalmente; palpo com um único artículo com nove cerdas. Tórax: asa danificada na preparação; escuto com duas fileiras irregulares dorsocentrais e duas laterais de cerdas; anepímero com um grupo de cerdas discais; anepisterno e catepisterno nús. Pernas quebradas. Abdômen: tergitos e esternitos I-VII esclerotinizados, retangulares, com cerdas em toda a sua extensão. Tergito VIII esclerotinizado, alongado, estreito e setoso; esternito VIII pouco esclerotinizado, retangular e setoso. Genitália: ovipositor estriado, pouco protátil, terminando em dois lobos setosos (Figs 16 e 17).

Larva. Amarela. Comprimento: $2,63 \mathrm{~mm}$. Antena cerca de duas vezes mais longa que larga; pescoço com um par de papilas ventrais não setosas. Espátula protorácica (comprimento: 0,25 $\mathrm{mm}$ ) com dois lobos medianos desenvolvidos e lobos laterais diminutos na extremidade anterior (Fig. 18); segmentos torácicos com um par de papilas não setosas, dois pares de papilas laterais setosas, dois pares de papilas pleurais (o par interno não setoso e o externo setoso) e dois pares de papilas dorsais setosas. Segmentos abdominais I-VIII com um par de papilas pleurais setosas; segmentos abdominais I-VII com dois pares de papilas dorsais setosas, dois pares de papilas ventrais (um par anterior e um par posterior) não setosas; segmento abdominal VIII com um par de papilas dorsais setosas, um par de papilas ventrais não setoso e espiráculo; 
segmento anal com dois pares de papilas terminais setosas; ânus arredondado. A larva empupa na galha.

Pupa e macho desconhecidos.

Holótipo fêmea. BRASIL: Rio de Janeiro, Arraial do Cabo, Restinga de Arraial do Cabo, 24-X-1987, V.C. Maia leg. (MNRJ). Uma larva de Rio de Janeiro, Maricá, Restinga de Barra de Maricá, 02-XII-1987, V.C. Maia leg., (MNRJ). Obtidos de galhas em Eugenia capacabanensis (Myrtaceae).

Galha. Vermelha, alongada e curva, unilocular, foliar (Figs 19, 20).

O nome específico refere-se ao aspecto espiralado da galha induzida por esta espécie.

\section{Stephomyia mina, sp.n.}

Figs 21-23

Diagnose. Palpo com um único artículo; macho com edeago alongado, glossiforme, sem reentrância mediana no ápice, hipoprocto formado por dois lobos completamente separados um do outro e com cerdas aproximadamente do mesmo comprimento, cerco formado por dois lobos riniformes, completamente separados um do outro.

Macho. Comprimento do corpo: 1,95-1,67mm; comprimento da asa: 1,34-1,50mm. Cabeça: olhos com facetas circulares intimamente aproximadas; antena: escapo de comprimento igual a sua largura, medindo $1,20-1,70$ vezes o comprimento do pedicelo, pedicelo com $0,60-0,80$ vezes a sua largura; 12 flagelômeros cilíndricos com circunfila anastomosada; palpo com um artículo; labelo com quatro cerdas laterais e quatro medianas; hipofaringe não setuloso no ápice. Tórax: Veias alares como em $S$. rotundifoliorum. Escuto com duas fileiras irregulares dorsocentrais e duas fileiras laterais de cerdas; anepímero e anepisterno com um grupo de cerdas discais, catepisterno nú. Pernas quebradas nos exemplares macho. Abdômen: tergitos e esternitos I-VII esclerotinizados, retangulares, com cerdas em toda a sua extensão. Tergito VIII esclerotinizado, alongado, estreito e setoso. Esternito VIII pouco esclerotinizado, retangular e setoso. Genitália: gonóstilo afilando em direção à extremidade livre; edeago glossiforme, sem reentrância mediana no ápice; hipoprocto formado por dois lobos ovalados setosos, completamente separados um do outro e com cerdas aproximadamente do mesmo comprimento entre si; cerco formado por dois lobos riniformes e setosos, completamente separados um do outro (Fig. 21).

Fêmea. Semelhante ao macho, diferindo no que segue. Comprimento do corpo: 2,50-2,30mm; comprimento da asa: 1,40-1,70mm. Cabeça: antena com 12 flagelômeros antenais cilíndricos, flagelômeros X-XII gradualmente mais curtos. Tórax: pernas com garras simples, curvas após o terço, e empódio com cerca de 2/3 do comprimento das garras. Genitália: ovipositor pouco protátil, estriado, terminando em dois lobos setosos (Fig. 22).

Pupa. Castanho-claro. Comprimento do corpo: 2,02-1,86mm. Cabeça: chifres antenais conspícuos; dentículo secundário inferior na base da cobertura 


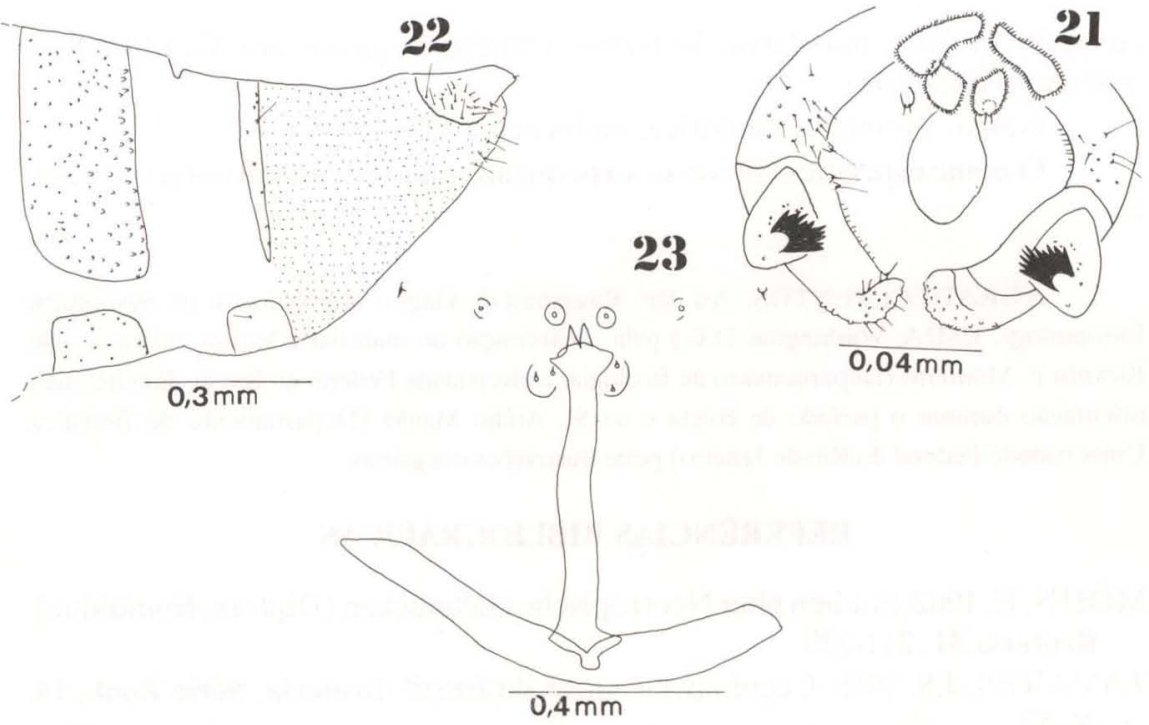

Figs 21-23. Stephomyia mina, sp.n. (21) Macho, genitália, vista dorsal; (22) fêmea, ovıpositor, vista lateral; (23) larva, espátula protorácica, vista ventral.

antenal; cerda apical mais curta que a largura da antena; espinhos frontais superior e inferior ausentes; região cefálica com duas projeções laterais esclerotinizadas na margem superior; papilas faciais ausentes. Tórax: espiráculo cilíndrico e curto $(0,05 \mathrm{~mm})$. Abdômen: cobertura das asas, do I, II, III pares de pernas atingindo, respectivamente, o limite dos segmentos abdominais III e IV; VII e VIII; dos terços médios e apical do segmento VII e no meio do segmento VII. Segmentos II-VIII com fileiras transversais de diminutos espinhos esclerotinizados distribuídos em toda a região dorsal.

Larva. Amarela. Comprimento: $1,92 \mathrm{~mm}$. Antena cerca de duas vezes mais longa qua larga; pescoço com um par de papilas ventrais não setosas. Espátula protorácica (comprimento: 0,17 mm) com dois dentes apicais longos e simples (Fig. 23); segmentos torácicos com um par de papilas esternais não setosas, dois pares de papilas laterais setosas, dois pares de papilas pleurais ( o par interno não setoso e o externo setoso) e dois pares de papilas dorsais setosas. Segmentos abdominais I-VIII com um par de papilas pleurais setosas; segmentos abdominais I-VII com dois pares de papilas dorsais setosas, dois pares de papilas ventrais (um par anterior e um par posterior) não setosas; segmento abdominal VIII com um par de papilas dorsais setosas, um par de papilas ventrais não setoso e espiráculo; segmento anal com dois pares de papilas terminais setosas; ânus arredondado. A larva empupa na galha.

Holótipo macho. BRASIL: Rio de Janeiro, Maricá, Restinga de Barra de Maricá, 18-III-1993, V.C. Maia leg. (MNRJ). Parátipos, com os mesmos dados do holótipo: uma fêmea, 15-I-1989; duas fêmeas, 10-IV-1992; uma fêmea, 09-III1993. Com os mesmos dados do holótipo: seis exúvias e duas pupas, 10-IV-1992; uma pupa, 30-XI-1992; cinco exúvias, 18-III-1993; duas larvas, 10-IV-1992; uma 
larva, 25-VI-1992; uma larva, 30-I-1993. Obtidos de galhas em Neomitranthes obscura (Myrtaceae).

Galha. Vermelha, cilíndrica, unilocular e foliar.

O nome específico refere-se ao pequeno comprimento do corpo do adulto.

AGRADECIMENTOS. Ao Dr. Raymond J. Gagné (Laboratory of Systematic Entomology, USDA, Washington D.C.) pela identificação do material e leitura crítica, ao Dr. Ricardo F. Monteiro (Departamento de Ecologia, Universidade Federal do Rio de Janeiro) pela orientação durante o período de coleta e ao Sr. Atídio Manhã (Departamento de Botânica, Universidade Federal do Rio de Janeiro) pelas ilustrações das galhas.

\section{REFERÊNCIAS BIBLIOGRÁFICAS}

MÖHN, E. 1962. Studien über Neotropische Gallmücken (Diptera, Itonididae). Broteria 31: 211-239.

TAVARES, J.S. 1916. Cecidomyias novas do Brazil. Broteria, Série Zool., 14: 36-57.

Recebido em 07.IV.1992; aceito em 02.II.1994. 